\title{
HUBUNGAN PELATIHAN APN DENGAN PENGETAHUAN DAN KETERAMPILAN BIDAN DALAM PERTOLONGAN PERSALINAN
}

\author{
Yuli Setiawati ${ }^{1}$, Nurafni Ani ${ }^{2}$ \\ ${ }^{1,2}$ FakultasKesehatan, Pertanian dan Kelautan, Prodi DIII Kebidanan Universitas \\ Muhammadiyah Palopo
}

\begin{abstract}
ABSTRAK
Komplikasi persalinan untuk ibu dan janin. Kematian ibu yang tinggi dipengaruhi oleh banyak faktor, salah satunya adalah kemampuan kerja bidan. Penelitian ini bertujuan untuk menilai pengaruh pelatihan terhadap pengetahuan dan keterampilan bidan APN serta perbedaan tingkat pengetahuan dan keterampilan bidan yang telah dilatih dan belum pernah dilatih APN. Penelitian ini adalah penelitian observasional yang hanya mengamati tanpa memperlakukan objek penelitian. Dalam penelitian ini penelitian ini adalah studi potong lintang dengan cara yang merupakan pendekatan observasi atau pengumpulan data sekaligus pada suatu waktu (Time Point Approach) artinya setiap subjek penelitian hanya diamati satu kali, dan pengukuran dilakukan pada status karakter atau variabel subjek pada saat inspeksi. Ini tidak berarti bahwa semua subjek penelitian diamati pada saat yang sama. Sampel dalam penelitian ini adalah semua populasi, 25 bidan di ruang bersalin di rumah sakit Sawerigading Palopo. Data dianalisis menggunakan uji chi-square. Hasil penelitian menunjukkan bahwa pelatihan APN memiliki hubungan yang signifikan dengan tenaga bantuan pengetahuan $(\mathrm{p}=0,025)$. Pelatihan APN memiliki hubungan yang signifikan dengan keterampilan bantuan persalinan $(\mathrm{p}=0,000)$. Kesimpulannya adalah bahwa pengetahuan dan keterampilan bidan yang telah dilatih oleh APN lebih baik daripada bidan yang tidak dilatih oleh APN.
\end{abstract}

\section{Kata kunci: bidan, terlatih APN, pengetahuan, keterampilan}

\begin{abstract}
Delivery complications for the mother and fetus. High maternal mortality is influenced by many factors, one of which is the ability of midwive'swork's. This study aied to assess the effect of training on knowledge and skills APN midwives as well as differences in the level of knowledge and skills of midwives ho have been trained and ho have never APN trained. This research is an observational research that is by simply observing without treating the object of study. In this study wwas a cross sectional study in a way that is an approach to observation or data collection at once at a time (Time Point Approach) means each subject of study only observed once, and the measurement is made on the status of the character or variable subjects at the time of inspection. This does not mean that all research subjects were observed at the same time. Samples in this research is all from populations, 25 midwives in the delivery room in hospital SawerigadingPalopo. Data were analyzed using chi-square test. The result showed that APN training has a significant association with knowledge help labor $(p=0,025)$. APN training has a significant connection with childbirth aid skills $(p=0,000)$. The conclusion that the knowledge and skills of midwives who have been trained APN better than the midwives who are not trained APN.
\end{abstract}

Keyword : midwives, APN trained, knowledge, skill

\section{PENDAHULUAN}

Masalah kematian ibu dan bayi di Indonesia masih merupakan masalah besar bagi bangsa. Survei Demografi Kesehatan Indonesia
(SDKI) tahun 2007 menunjukkan Angka Kematian Ibu (AKI) 228 per 100.000 kelahiran hidup, pada tahun 2012 meningkat menjadi 359 per 100.000 kelahiran hidup, sementara pada 
tahun 2015 ditargetkan menjadi 102 per 100.000 kelahiran hidup. Angka Kematian Ibu di RSUD Sawerigading Palopo tahun 2014 sebanyak 4 orang, 1 orang diantaranya meninggal karena penyulit kehamilan dan persalinan s ementara 3 orang lainnyameninggal karena eklampsia (Profil RSUD SawerigadingPalopo, 2016).

Menurut data SKRT tahun 2001, penyebab kematian ibu di Indonesia adalah sebagai berikut; perdarahan (28\%), eklamsia (24\%), infeksi (11\%), komplikasi puerperium $(8 \%)$, persalinanmacet $(5 \%)$,abortus $(5 \%)$, trauma obstetric (3\%) emboli obstetric (3\%) dan penyebab lain (11\%). (Kadirsaja, 2014)

Sedangkanuntuk data Angka kematian bayi (AKB) di Indonesia walaupun masih jauh dari angka target MDGs yaitu Jumlah anak yang meninggaladalah salah satu indicator kesehatan yang sangat penting. MDG 4 menargetkan penurunan angka kematian anak (AKA) tahun 1990 sebanyak dua pertiganya. Hasil SDKI tahun 1991 menunjukkan bahwa AKA adalah 97 kematian per 1.000 kelahiran hidup. Artinya, target AKA di Indonesia pada tahun 2015 adalah 32 kematian per 1.000 kelahiran.

Hasil sementara SDKI tahun 2012 mengindikasikanbahwa AKA menurunmenjadi 40 kematian per 1.000 kelahiranhidup. AKA mencakupAngkaKematianBayi (AKB) di dalamnya. Berdasarkanhasil SDKI tahun 1991, AKB mencapai 68 kematian per 1.000 kelahiran hidup. Iniberarti pada tahun 2015 diharapkan AKB dapat diturunkan menjadi 22 kematian per 1.000 kelahiranhidup.

Hasil sementara SDKI 2012 memperlihatkan bahwa AKB menurun menjadi 32 kematian per 1.000 kelahiran hidup. Angka Kematian Bayi di RSUD Sawerigading tahun 2016 sebanyak 67 bayi. Adapun penyebab kematian bayi yaitu penyakit ibu (1 bayi), Pertumbuhan Janin Terhambat (16 bayi), Hipoksia\&asfiksia (12 Bayi), Gangguan saluran nafas pada masa perinatal (35 bayi), kondisi lain (1 bayi) (Profil RSUD SawerigadingPalopo, 2015).

Diperkirakan pada tahun 2015 target AKA dan AKB akan dapat dicapai.Adapun penyebab kematian adalah BBLR (29\%), asfiksia (27\%), masalah pemberian minum $(10 \%)$,tetanus $(10 \%)$, gangguan hematologik
(6\%), infeksi (5\%) dan penyebab lain (13\%) (BKKBN \& IBI, 2015)

Kira-kira 90\% kematian ibu terjadi disaat persalinan dan kira-kira 95\% penyebab kematian ibu adalah komplikasi obstetric yang sering tidak dapat diperkirakan sebelumnya, maka kebijaksanaan Departemen Kesehatan untuk mempercepat penurunan AKI adalah mengupayakan agar setiap persalinan ditolong atau minimal didampingi oleh bidan dan pelayanan obstetric sedekat mungkin kepada semua ibu hamil (Prawirohardjo.S, 2006)

Mengingatpentingnya peningkatan kesehatan ibu dan bayi baru lahir maka pada tanggal 12 Oktober 2000 pemerintah telah mencanangkan Gerakan Nasional Kehamilan dan Persalinan Yang Aman atau Making Pregnancy Safer (MPS) yang merupakan bagian dari program Safe Motherhood. Sebagai Strategi Pembangunan Kesehatan Masyarakat menuju Indonesia sehat 2010, MPS bertujuan melindungi hak reproduksi dan hak asasi manusiadengan cara mengurangi beban kesakitan ,kecacatan dan kematian yang berhubungan dengan kehamilan dan persalinan yang sebenarnya tidak perlu terjadi (Depkes RI, 2001)

Sejalan dengan Visi MPS yaitu semua perempuan di Indonesia dapat menjalani kehamilan dan persalinan dengan aman serta bayi yang dilahirkanhidup dan sehat dan Misi yang merupakan penjabaran dari Visi di atasadalah menurunkan angkakesakitan dan kematian maternal dan neonatal melalui system kesehatanuntukmenjaminaksesterhadapintervens i yang CostEffective.

Bidan adalah seorang perempuan yang telah menyelesaikan Program Pendidikan Bidan, diakui oleh Negara serta memperoleh kualifikasi dan diberi izin untuk menjalankan praktek kebidanan. Bidan dalam menjalankan fungsi dan tugasnya didasarkan pada kompetensi dan kewenangan yang diberikan yang diaturmelalui Peraturan Menteri Kesehatan (PERMENKES)

No.900/MENKES/SK/VIII/2000. Bidan sebagai suatu profesi disiapkan melalui pendidikan formal agar lulusannya dapat melaksanakan pekerjaan yang menjadi tanggung jawabnya secara professional. Keberadaan bidan di Indonesia sangat diperlukan untuk 
meningkatkan kesejahteraan ibu dan bayinya (Zein A, 2005)

\section{METODE \\ JenisPenelitian}

Jenis penelitian ini adalah observasional yaitu dengan hanya mengamati dan melakukan perlakuan pada obyek penelitian

\section{Lokasi dan Waktu Penelitian}

Penelitian ini bertempat di RSUD Sawerigading Palopo dengan mengambil lokasi di kamar bersalin. Penelitian dilaksanakan pada bulan September 2017 sampai April 2018.

\section{Populasi dan Sampel}

Populasi penelitian adalah seluruh bidan yang ada di kamarbersalin RSUD Sawerigading Palopo. Sampel penelitian ini dilakukan pada seluruh populasi.

\section{Pengumpulan Data}

Pengumpulan data dilakukan dengan cara pengamatan langsung serta pencatatan langsung terhadap objek yang diteliti. Observasi dilakukan oleh peneliti dengan cara pengamatan mengenai : Penerapan APN oleh bidan dengan menggunakan lembar checklist. Kemudian pembagian kuesionerkepadabidan. Pertanyaan dengan bentuk skala Guttman dan terdiridari 20 pertanyaan. Jawaban pertanyaan adalah pernyataan benar dan salah dengan menggunakan checklist dengan interpretasi penilaian, pemberian skor pengetahuan responden untuk pertanyaan positif $(+)$. Data yang dikumpulkantersebutdianalisadengan uji HASIL korelasi, dengan derajat kepercayaan 95\% ( $\alpha=$ 0,05). Data ditabulasi dan dianalisis menggunakan teknik komputerisasi .

Guna mengetahui secara lebih tepat besar I derajat pengaruh dua variable digunakan koefisien korelasi Pearson Product Moment, dimana koefisien korelasi disimbolkan dengan huruf r. nilai korelasi (r) berkisar 0 sampai 1 atau bila dengan arah nilainya antara -1 sampai 1.

Hubungan dua variable dapat berpola positif maupunnegatif. Hubungan positif terjadi bila kenaikan variabel yang lain. Menurut Colton, kekuatan hubungan dua variable secara kualitatif dapat dibagi dalam 4 area yaitu: $\mathrm{r}=$ 0,00 - 0,25 tidak ada hubungan / hubungan lemah, $r=0,26-0,50$ hubungan sedang, $r=$ $0,51-0,75$ hubungan kuat, $r=0,76-1,00$ hubungan sangat kuat / sempurna.

\section{Pengolahan dan Analisis Data}

Analisis berupa analisis univariat dan bivariat merupakan analisa hasil dari variabel-variabel bebas yang diduga mempunyai hubungan dengan variable terkait. Analisis data yang digunakan adalah uji Chi-Square. Sehingga dapat diketahui ada atau tidaknya pengaruh secara statistik, dengan menggunakan program computer SPSS for windows. Melaluiuji ChiSquare selanjutnya ditarik suatu kesimpulan, bila nilai $p<0,05$ maka Ha diterima, yang menunjukkan adanya hubungan antara variable terikat dengan variable bebas. Sedangkan bila nilai $p>0,05$ maka Ho ditolak, yang menunjukkan Tidak ada hubungan antara variable terikat dengan variable bebas.

\section{Tabel 4.1.Karakteristik Responden di RSUD Sawerigading Palopo}

\begin{tabular}{llll}
\hline NO & KarakteristikResponden & Jumlah (n) & Persentase (\%) \\
\hline 1 & Umur & & \\
& Reproduksi Sehat (20-35 Tahun) & 23 & 92 \\
& & & \\
& Reproduksi Kurang Sehat (>35 Tahun) & 2 & 8 \\
\hline & Total & 25 & 100 \\
\hline 2 & Pendidikan & & \\
& DIII & 15 & 60.00 \\
& DIV & 10 & 40.00
\end{tabular}




\begin{tabular}{llrc}
\hline & Total & 25 & 100 \\
\hline 3 & Masa Kerja & & \\
& $<10$ Tahun & 22 & 88.00 \\
& $>10$ Tahun & 3 & 8.00 \\
\hline & Total & 25 & 100
\end{tabular}

Berdasarkan tabel 4.1 menunjukkan yang berpendidikan DIII sebanyak yaitu 15 bahwa dari 25 responden mayoritas berumur orang $(60 \%)$, dan yang berpendidikan DIV reproduksi sehat sebanyak 23 orang (92\%), yaitu 10 orang (40\%). Adapun responden yang sedangkan responden dengan umur reproduksi memiliki masa kerja kurang dari 10 tahun yaitu kurang sehat sebanyak 2 orang $(8 \%)$. 22 orang $(88 \%)$, dan yang memiliki masa kerja Berdasarkan pendidikan, mayoritas responden lebih dari 10 tahun yaitu 3 orang $(8 \%)$.

\begin{tabular}{clcc}
\multicolumn{5}{c}{ Tabel 4.2 } & \multicolumn{3}{c}{ Distribusi Frekuensi Responden berdasarkan Pengetahuan } \\
\hline NO & Karakteristik Responden & Jumlah (n) & Persentase (\%) \\
\hline $\mathbf{1}$ & Pengetahuan & & \\
& Cukup & 20 & 80.00 \\
& Kurang & 5 & 20.00 \\
\hline & Total & 25 & 100 \\
\hline
\end{tabular}

Berdasarkan tabel 4.2 menunjukkan bahwa dari 25 responden yang berpengetahuan responden dengan tingkat pengetahuan kurang cukup yaitu 20 orang (80\%), sedangkan yaitu 5 orang $(20 \%)$.

Tabel 4.3 Distribusi Frekuensi Responden berdasarkan Keterampilan

\begin{tabular}{|c|c|c|c|}
\hline NO & Karakteristik Responden & Jumlah (n) & Persentase (\%) \\
\hline 1 & Mahir & 17 & 68.00 \\
\hline \multirow[t]{2}{*}{2} & Mampu & 8 & 32.00 \\
\hline & Total & 25 & 100 \\
\hline
\end{tabular}

Berdasarkan Tabel 4.3 menunjukkan bahwa dari 25 responden yang memiliki keterampilan mahir yaitu 17 orang $(68 \%)$, sedangkan, yang memiliki keterampilan mampu yaitu 8 orang $(32 \%)$. 
Tabel 4.4. Hubungan pelatihan APN dengan tingkat pengetahuan pertolongan persalinan oleh bidan di RSUD Sawerigading Kota Palopo

\begin{tabular}{|c|c|c|c|c|c|c|c|}
\hline \multirow{3}{*}{ Variabel } & \multicolumn{4}{|c|}{ Pengetahuan } & \multirow{3}{*}{ Total } & \multirow{3}{*}{$\%$} & \multirow{3}{*}{ Nilai $p$} \\
\hline & \multicolumn{2}{|c|}{ Cukup } & \multicolumn{2}{|c|}{ Kurang } & & & \\
\hline & f & $\%$ & $\mathbf{F}$ & $\%$ & & & \\
\hline \multicolumn{8}{|l|}{ Pelatihan APN } \\
\hline Pernah & 18 & 85,7 & 3 & 14,28 & 21 & 100 & \\
\hline BelumPernah & 2 & 50 & 2 & 50 & 4 & 100 & 0,025 \\
\hline Total & 20 & & 5 & & 25 & & \\
\hline
\end{tabular}

Pada Tabel 4.6 dapat diketahui Hubungan pelatihan APN dengan tingkat

\section{a. Pengetahuan}

Dari 25 responden yang memiliki pengetahuan cukup yaitu 20 orang, pernah mengikuti pelatihan APN 18 orang $(85,7 \%)$ dan belum pernah mengikuti pelatihan APN 2 orang $(50 \%)$. Sedangkan 5 orang responden memiliki pengetahuan kurang, pernah mengikuti pengetahuan pertolongan persalinan oleh bidan adalah sebagai berikut:

pelatihan APN 3 orang $(14,28 \%)$ dan yang belum pernah mengikuti pelatihan APN 2 orang $(50 \%)$. Berdasarkan uji analitik chisquare didapati $(p=0,025<0,05)$ hal ini berarti bahwa pelatihan APN mampu meningkatkan pengetahuan bidan dalam pertolongan persalinan walaupun kekuatannya sangat lemah

\section{b. Keterampilan}

Tabel. 4.5 Hubungan Pelatihan APN dengan tingkat Keterampilan Pertolongan Persalinan oleh Bidan di RSUD Sawerigading Kota Palopo

\begin{tabular}{|c|c|c|c|c|c|c|c|}
\hline \multirow{3}{*}{ Variabel } & \multicolumn{4}{|c|}{ Keterampilan } & \multirow{3}{*}{ Total } & \multirow{3}{*}{$\%$} & \multirow{3}{*}{ Nilai $p$} \\
\hline & \multicolumn{2}{|c|}{ Mahir } & \multicolumn{2}{|c|}{ Mampu } & & & \\
\hline & $\mathbf{F}$ & $\%$ & $\mathbf{F}$ & $\%$ & & & \\
\hline \multicolumn{8}{|l|}{ Pelatihan APN } \\
\hline Pernah & 13 & 68,42 & 6 & 31,57 & 19 & 100 & \\
\hline BelumPernah & 4 & 66,7 & 2 & 33,33 & 6 & 100 & 0,000 \\
\hline Total & 17 & & 8 & & 25 & & \\
\hline
\end{tabular}

Dari 25 responden yang memiliki keterampilan mahir yaitu 17 orang, pernah mengikuti pelatihan APN 13 orang $(68,42 \%)$ dan belum pernah mengikuti pelatihan APN 4 orang $(66,7 \%)$. Sedangkan 8 orang responden memiliki keterampilan mampu, pernah mengikuti pelatihan APN 6 orang $(31,57 \%)$ dan

\section{PEMBAHASAN}

\section{Tingkat Pengetahuan dan Keterampilan} Bidan Tentang APN.

Kinerja yang didasari oleh pengetahuan akan langgeng dari pada tidak didasari oleh pengetahuan (Notoatmodjo, 2010). Berdasarkan hasil analisis univariat pada tabel 4.2 diatas menunjukkan bahwa tingkat pengetahuan bidan yang belum pernah mengikuti pelatihan APN 2 orang $(33,33 \%)$. Berdasarkan uji analitik chisquare didapati $(p=0,000<0,05)$, dengan demikian maka Ho ditolak. Hal ini berarti bahwa pelatihan APN mampu meningkatkan keterampilan bidan dalam pertolongan persalinan.

Pengetahuan merupakan domain yang sangat penting untuk terbentuknya kinerja seseorang. dalam pertolongan persalinan sudah cukup sebesar 20 responden (80\%) dan masih ada pengetahuan bidan tentang APN berpengetahuan kurang sebesar 5 orang (20\%). Menurut asumsi peneliti, bagi bidan yang berpengetahuan baik 
karena bidan tersebut sudah mendapatkan pelatihan dan sosialisasi tentang APN, adanya sikap yang mendukung dalam melaksanakan standar APN sehingga peningkatan pengetahuan berimplikasi terhadap perilaku bidan dalam melaksanakan penerapan standar APN.

Keterampilan bidan dalam penelitian ini adalah keterampilan dalam hal mengenali gejala dan tanda kala II, menyiapkan pertolongan persalinan, memastikan pembukaan sudah lengkap dan keadaan janin baik, menyiapkan ibu dan keluargau ntuk membantu proses bimbingan

\section{KESIMPULAN DAN SARAN}

Pelatihan APN mempunyai hubungan yang signifikan dengan pengetahuan pertolongan persalinan bidan dan dengan keterampilan pertolongan persalinan bidan. Artinya bahwa pelatihan APN mampu meningkatkan pengetahuan dan keterampilan bidan akan pertolongan persalinan. Pengetahuan

\section{DAFTAR PUSTAKA}

Anita. (2009). Hubungan Kompetensi Bidan Dalam Pelaksanaan Asuhan Persalinan Normal di Kabupaten Aceh Besar .

BKKBN, IBI. (2015). Standar pelayanan Kebidanan, Jakarta.

Departemen Kesehatan RI,(2014). Pengembangan Manajemen Kinerja Klinik, Jakarta.

Depkes RI. (2010). Acuan Pelatihan APN Bina Kesehatan Masyarakat.

Depkes RI. (2012). KebijakanPengembangan Tenaga Kesehatan, Jakarta.

Dep Kes RI. (2008). Rencana Strategis Nasional Making Pregnancy Safer (MPS) di Indonesia 2001-2010, Jakarta.

Gibson, J. L, at al. (2012) Organisasi Perilaku, Struktur, Proses, Jilid I, Edisi VIII, Andriani, N (Alih Bahasa) Bina Rupa Aksara, Jakarta.

Kadirajasa. (2014). Patologi Kehamilan dan Persalinan, BumiAksara, Jakarta.

Kurniati E. (2012). Hubungan Pelatihan Asuhan Persalinan Normal Dengan Pengetahuan dan Keterampilan Bidan Desa Dalam Pertolongan Persalinan di Kota Gorontalo meneran, persiapan pertolongan kelahiran, persiapan pertolongan kelahiran bayi, penanganan bayi baru lahir, penatalaksanaan kala III, menilai perdarahan, melakukan prosedur pasca persalinan.

Tingkat keterampilan bidan dalam pertolongan persalinan dapat dilihat pada tabel 4.5 dimana data yang ada memperlihatkan hasil bahwa dari 25 bidan yang ada di kamar bersalin RSUD Sawerigading Kota Palopo, keterampilan bidan mengenai pertolongan persalinan kategori mahir lebih tinggi (68\%) dari kategori mampu (32\%).

pertolongan persalinan bidan yang telah dilatih APN lebih baik dari pengetahuan bidan yang belum dilatih APN begitu juga keterampilan pertolongan persalinan bidan yang telah dilatih APN lebih baik dari bidan yang belum dilatih APN.

Mahmudi. (2014) Manajemen Kinerja Sektor Publik, AkademiManajemen Perusahaan YKPN, Yogyakarta.

Novrida P. (2013). Hubungan Pengetahuan, Sikap dan Beban Kerja Dengan Kelengkapan Pendokumentasian Asuhan Kebidanan Di RSU Pusat Sanglah Denpasar Diakses pada tanggal 17 mei 2015 Available from : http://alumni.Unudac.id/kumpulanfile/ 59090815323 abs. pdf

Prawirohardjo.S, Acuan Nasional Pelayanan Kesehatan Maternal dan Neonatal, Yayasan Bina Pustaka, Jakarta.

Profil RSUD Sawerigading Palopo, 2016.

Rodiah. (2011). Pengaruh Pengetahuan dan Sikap Bidan dengan Penerapan Asuhan Persalinan Normal di Rumah Bersalin Ngudi Saras Karanganyar.

Sastrohadiwiryo. S. (2006). Manajemen Tenaga Kerja Indonesia, Pendekatan Administratif dan Operasional, Bumi Aksara, Jakarta.

Sugiyono. (2006). Metode Penelitian Kuantitatif, Kualitatif dan R \& D, Penerbit Alfa Beta, Bandung. 